\title{
Prevalence of Dermatophytic Infection among Diabetic and Non-Diabetic Patients in a Tertiary Level Hospital in Chennai, India
}

\author{
Dinesh Kaliyamoorthi* \\ No 4, Z-Block, Plot No1106, 11Street, Anna Nagar, Chennai-600040, India \\ *Corresponding author
}

\begin{tabular}{|c|}
\hline Keywords \\
\hline $\begin{array}{l}\text { Trichophyton } \\
\text { rubrum, } T \text {. } \\
\text { mentagrophyte } \\
\text { Epidermophyton } \\
\text { floccosum, Diabetic } \\
\text { patients, Non- } \\
\text { diabetic patients }\end{array}$ \\
\hline Article Info \\
\hline $\begin{array}{l}\text { Accepted: } \\
20 \text { May } 2018 \\
\text { Available Online: } \\
\text { 10 June } 2018\end{array}$ \\
\hline
\end{tabular}

\section{A B S T R A C T}

Diabetes mellitus is the most common endocrine disorder and takes on pandemic proportions. Dermatophytosis remains a significant public health problem. The objective of the study was to study the prevalence of Dermatophytic infection among diabetic and non- diabetic patients. It is a cross sectional study conducted during July 2011 to July 2012. All clinically diagnosed cases of dermatophytosis attending the Dermatology OPD of were included in the study. Among those 40 diabetic and 40 non diabetic Patients were included. Clinical materials were collected from the patients suffering from various types of dermatophytoses and processed according to standard protocols. 80 Samples from 80 patients suspected of dermatophytic infections were collected and processed. It includes 40 diabetic patients and 40 non-diabetic patients. The male /female ratio was 51\%: $48 \%$. Patients above 40 years of age were taken from both diabetic and non non-diabetic patients. A $16.3 \%$ of cases gave a history of contact with possible source of infection. Of the 40 diabetic samples collected 7 samples $(17.5 \%)$ were both negative for both $\mathrm{KOH}$ wet mount and culture, remaining 33 samples $(82.5 \%)$ were positive for both $\mathrm{KOH}$ mount and culture. Out of the 40 non-diabetic patients 12 samples (30\%) were negative for both $\mathrm{KOH}$ mount and culture, remaining $28(70 \%)$ were positive for both $\mathrm{KOH}$ mount and culture. The samples were skin scrapings, hair, and nail. Of the culture positive cases, 58.7\% belonged to Trichophyton spp., 15\% Microsporum spp. and 2.5\% to Epidermophyton spp. The predominant isolate from all samples were T. rubrum, $40 \%$ from both diabetic and non-diabetic patients. T. rubrum was found predominantly in diabetic patients with an isolation rate of $45 \%$ than in the non-diabetic patients were the isolation rate is $35 \%$. $T$. mentagrophyte isolation rate was $18.7 \%$ from both diabetic and non-diabetic patients. Isolation rate of $T$. mentagrophyte was more from non-diabetic patients $(20 \%)$ than the diabetic patient with the isolation rate of $17.5 \%$. Microsporum gypseum isolation rate was $15 \%$ from both diabetic and non-diabetic patients. Isolation rate of M. gypseum (15\%) was same among both diabetic and non-diabetic patients. Epidermophyton floccosum was the least isolated dermatophyte with an isolation rate of 5\% and it was isolated only from diabetic patients. The predominant isolate from all samples were T. rubrum, $40 \%$ from both diabetic and non-diabetic patients. 


\section{Introduction}

Diabetes mellitus is the most common endocrine disorder and takes on pandemic proportions.

Worldwide, over 246 million people suffer from the disease in 2007 and estimates for 2025 are depicted at a total of 380 million patients (Van Houtum, 2008). Diabetes mellitus (DM) is characterized by state of relative or complete insulin deficiency, leading to gross defects in glucose, fat and protein metabolism (Bub and Olerud, 2003). It is very unfortunate that India tops the list in diabetic population. World health organisation (WHO) estimates the diabetic population in India in 2000 is 31.7 million and in 2030 it is likely to rise to 79.4 million (Wilds Roglic et al., 2004).

A wide variety of cutaneous infections in man are present worldwide in which the integuments and its appendages the hair and the nail are involved. Majority of the infections are caused by a homogenous group of keratophilic fungus called the dermatophytes. Dermatophytes are fungi that can cause infections of the skin, hair and nails due to their ability to utilize keratin. The fungi are the commonest infective agent of man and no group of people or geographical areas are without taenia or ringworm infection (taenialatin for worm). Evolutionary development towards an accommodating host parasite relationship can be seen among the dermatophyte which is absent among other fungal agent of human disease. This group of disease is collectively referred to as dermatophytosis.

Depending on the species, the organism may be viable in the environment for up to 15 months.

There is an increased susceptibility to infection when there is a pre-existing injury to the skin such as scars, burns, excessive temperature and humidity.

Dermatophytes are classified as anthropophilic, zoophilic or geophilic according to their normal habitat.

Anthropophilic dermatophytes are restricted to human hosts and produce a mild, chronic inflammation.

Zoophilic organisms are found primarily in animals and cause marked inflammatory reactions in humans who have contact with infected cats, dogs, cattle, horses, birds, or other animals. This is followed by a rapid termination of the infection.

Geophilic species are usually recovered from the soil but occasionally infect humans and animals. They cause a marked inflammatory reaction, which limits the spread of the infection and may lead to a spontaneous cure but may also leave scars.

\section{At the National Centre for Mycology}

About $58 \%$ of the dermatophyte species isolated are Trichophyton rubrum

$27 \%$ are T.mentagrophytes

$7 \%$ are T.verrucosum

$3 \%$ are T.tonsurans

Infrequently isolated (less than 1\%) are Epidermatophyton floccosum, Microsporum audouinii, M.canis, M.equinum, M.nanum, M.persicolor, Trichophyton equinum, T.kanei, T.raubitschekii, and T.violaceum.

Skin manifestations in diabetes mellitus are common and expressed in numerous forms. If one considers metabolic effects on microcirculation and changes in skin collagen, prevalence approaches $100 \%$. Findings range 
from the presenting manifestations of the disease to signs of long term involvement, and serious or even life threatening problems. For all of these, recognition is the key to treatment and/or prevention (The Electronic textbook of Dermatology). Non-Diabetic patients are also prone to dermatophytic infection because of their poor hygiene in low socio economic group and the environment they live in also plays as an etiological cause. The common dermatophyte encountered in non-diabetic patients is T.rubrum, T.mentagrophyte, M.gypseum.

Superficial fungal infections of the foot (tinea pedis and onychomycosis) are common among elderly patients. Although most authorities believe that patients with diabetes mellitus have an increased predisposition to dermatophytic infections, some controversies still remain. Because these infections disrupt the skin integrity and provide an avenue for bacterial superinfection, elderly diabetic patients with dermatophytic infection should be promptly treated with an antifungal agent. For most dermatophytic infections of the foot, topical agents are usually effective and less expensive than oral agents (Foot Fungus in Diabetics, 2004).

Recent studies show greater incidence of skin infections in diabetic patients. Incidence ranges from 20-50\%, (Hattemn et al., 2008) mostly in type 2 diabetes mellitus and often associated with poor glycemic control (Nigham and Pande, 2003). Infections constitute the main bulk of cutaneous manifestations of diabetes mellitus (Mahajan et al., 2003).

Association of dermatophyte infection with diabetes is controversial but recent data shows a statistically significant relationship (Aananthi and Sarayu, 2005). Common superficial infections are caused by Trichophyton rubrum, T.mentagrophytes, and Epidermophyton floccosum.
In diabetic patients, onychomycosis or tinea pedis should be monitored and treated, as it can be part of entry for infection. This is especially true for patients with neurovascular complications and intertrigo.

Signs of T.rubrum infection are noninflamed, white, powdery scaling of skin creases on the palms and soles, often with nail involvement. T.mentagrophytes-associated intertrigo or interdigital infection presents as maceration and superficial scaling with an active red border (Hattemn et al., 2008).

To isolate the dermatophytes from clinical specimens like skin, nail and hair obtained from patients attending Dermatology OP.

To speciate the isolates of dematophytes.

To study the correlation of fungal isolates and the clinical manifestations.

To determine the commonest prevalent genus and species of dermatophytes in and around Chrompet Chennai.

To determine the antifungal susceptibility of the isolates by different methods

\section{Materials and Methods}

\section{Materials}

Sterilized equipments were used at all times to avoid contamination by non-pathogenic fungi and bacteria. The following equipments and the media were used for the collection of specimens from the patients and the isolation and identification of the etiologic agents.

\section{Equipments}

Ultraviolet lamp

Woods lamp

Epilated forceps

Nail clipper 
Scalpel

Scissors

Inoculating needles

Sterile test tubes and petri-dishes

Clean slides

Sterile cotton

\section{Reagents}

Seventy percent alcohol

Ten to fifteen percent Potassium hydroxide solution

Cycloheximide and chloramphenicol

\section{Stain}

Lactophenol cotton blue

\section{Specimen}

The clinical material collected from the patients includes:

Skin scraping

Nail clipping

Hair from infected area

\section{Media used}

For the isolation and identification of the etiological agents the following media were used.

\section{Sabourauds cycloheximide chloramphenicol medium.}

This is a selective medium (69) for the isolation of pathogenic fungi from heavily contaminated clinical materials such as hair, skin scrapings and nail Clippings. Chloramphenicol inhibits the growth of most contaminating bacteria and cycliheximide suppresses the growth of many saprophytic fungi.

Clinical materials were collected from the patients suffering from various types of dermatophyteses. Proper selection of clinical materials was very important for both direct examination and culture. The types of specimen collected include:-

\section{Skin scrapings}

Scraping was obtained from the lesions involving the skin with a sterile scalpel after carefully washing the site with 70 percent alcohol. Scrapings taken from active border areas of lesions were placed in sterile petridish for laboratory examination and culture. In some lesions vesicles were present which were carefully clipped off with small sterile scissors and successful microscopic and cultural examinations were made (fig:)

\section{Nail clipping}

Ringworm infected nails were found to be thickened and deformed. Clipping of nail, especially near the bed of the nail were collected in a sterile petri-dish for microscopic examination and culture. (fig:)

\section{Hair}

The patients suffering from dermatophytic infection were examined under normal light for area without hair, scaling, crust formation, hair stumps and erythema. The tinea capitis patients were then subjected to woods light examination in a dark room to determine the fluroscence. The basal portion of the hair or the hair tufts were collected as the fungus is usually found in this area

\section{Sample Population}

Cross sectional study from January 2010 to July 2012.All clinically diagnosed cases of dermatophytosis attending the Dermatology OPD of Sree Balaji Medical College and Hospital were included. Among those 40 
DIABETIC and 40 NON DIABETIC Patients were included. Patients using antifungal treatment for $>3$ weeks were excluded. Direct microscopy and culture of relevant samples were done.

\section{Microscopic examination of clinical materials}

The clinical material so obtained was dissolved in two drops of 10 percent potassium hydroxide on a glass slide. If the nail clipping were thick 15 percent potassium hydroxide was used. After putting the cover slip the slide was heated for few seconds over spirit lamp taking care that the material should not boil. The preparation was observed under the low power of the microscope in reduced light. Presence of mycelia fragments and the distribution of spores on or inside the hair were noted. For a detailed microscopic morphology of the etiologic agent in clinical material, the slide preparation was studied under the high power of the microscope and the observation was recorded as follows.

\section{Direct examination in potassium hydroxide mount}

\section{Skin scraping and nail}

Branching mycelia elements with or without chains of arthrospores or mycelium and masses of arthrospores, some in chains

\section{Hair}

Endotherix or ectotherix infection, sheath of small spores in mosaic inside or outside the hair, or mycelium with hair.

\section{Isolation of etiological agents}

\section{Medium}

Sabourauds cycloheximide chloramphenicol medium was used for the isolation of the dermatophyte from the clinical material.

\section{Inoculation of slant}

Slants were inoculated by placing hair, skin scrapings or nail clipping with the help of a sterile needle on slant surface of the medium.

\section{Incubation}

All the tubes inoculated were incubated at room temperature about $27^{\circ} \mathrm{c}$ to $30^{\circ} \mathrm{c}$ for one to three weeks. Slants were examined every four to six days. If any saprophytic fungi appeared, the suspected colony of dermatophyte was transferred to other slant.

\section{Identification}

After incubation the slant were examined for any growth, different dermatophyte show different type of growth and colour variation.

\section{Microscopic examination of fungi by lactophenol cotton blue preparation}

This is to identify the filamentous fungi

Different methods are followed to prepare fungal cultures for microscopic examination by Lacto phenol cotton blue (LCB) preparation. They are

Tease mount preparation

Scotch tape preparation

Slide culture

\section{Lactophenol cotton blue stain}

Phenol crystals - 20.00 grams

Lactic acid - 20.00 grams

Glycerol - $40 \mathrm{ml}$

Distilled water - $20 \mathrm{ml}$

Dissolve the ingredients by heating the container in a hot water bath. Add 0.05 gram cotton blue. 


\section{Scotch Tape Preparation}

Fungal growth adheres to the adhesive side of the tape so that the colony can be easily examined by touching them with the tape

\section{Method}

Place a drop of LCB on a clean slide

Touch the adhesive side of the tape of transparent scotch tapes on the surface of the colony at a point intermediate between its center and the periphery

Fix the adhesive side of the tape over an area on the glass slide containing the LCB. Examine microscopically the preparation under 10x, 45x.

\section{Tease Mount Preparation}

Place a drop of lactophenol cotton blue on a clean glass microscopic slide

With a straight wire slightly bent at the tip remove a small portion of the colony and the supporting agar at a point mid-way between the centre and periphery and place it in the drop of LCB

With the help of another straight wire or needle tease the fungal culture tint small bits and spread in LCB

Place a cover slip and apply gentle pressure over the agar bits to spread evenly.

Examine microscopically after giving sufficient time for the structures to take up the strain, usually 30 minutes

\section{Slide Culture}

Place inside a $9 \mathrm{~cm}$ glass petridish a $\mathrm{v}$ shaped bent glass rod, a microscopic glass slide, and two cover slip. Wrap them in brown paper and sterilize in a hot air oven at $160^{\circ} \mathrm{c}$ for 1 hour.
Flames sterilize the scalpel, cool and cut a small square agar block from SDA plate and place it on the glass slide.

With the help of an inoculating needle, remove the growth from the colony with the supporting agar and place it on the glass slide.

With the help of inoculating needles tease it in to small bits and transfer them to the corners and edges of the agar block.

Place a cover slip over the agar and gently press it to seat firmly on the agar.

Pour about $10 \mathrm{ml}$ sterile distilled water into the petridish, cover and incubate at room temperature $\left(25-30^{\circ} \mathrm{c}\right)$.

Examine the preparation every 48 hours for the growth to occur over the cover slip and slide.

When sufficient growth has occurred the cover slip is removed with a sterile forceps and transferred to a drop of LCB on a glass microscopic slide.

Remove the agar block and discard in the discarding jar. Add a drop of LCB to the growth on the glass slide and cover it with a cover slip. Thus we get two LCB mounts from one slide culture preparation

Examine LCB mount at $10 \mathrm{x}, 45 \mathrm{x}$ for characteristic morphology.

\section{KOH Preparation}

Direct examination of clinical specimens provides an immediate presumptive diagnosis of type of fungal infections. It also aids in the selection of appropriate culture media for the isolation of the etiological agent. $\mathrm{KOH}$ clears out the background scales or cell membranes 
that may be confused with hyphal elements of fungi. Clearing is usually accelerated by gently heating.

A drop of $10 \% \mathrm{KOH}$ is kept on a microscopic slide and emulsify the specimen with the help of loop and place a cover slip, leave it for 10 minutes and examine under microscope.

\section{General characteristic of dermatophyte}

\section{Trichophyton rubrum}

Rugal folds are seen on the surface

The reverse side of the colony is yellow when young and becomes reddish to rose purple with age

Macroconidia are generally absent

Microconidia present in large numbers

\section{Trichophyton mentagrophyte}

Fluffy granular white growth is seen in tube

Reverse is buff or reddish brown

Macroconidia rarely seen

Microconidia produced in large numbers

\section{Epidermophyton floccosum}

Velvety to powdery surface

Surface is folded in number of radiating furrows

Macroconidia are calvate, smooth, and fairly thick walled

Microconidia not produced.

Microsporium gypseum
Cinnamon coloured, reverse of the colony is light tan

Large number of macroconidia are produced

Microconidia are rarely seen

\section{Results and Discussion}

The work represents a comprehensive study of the dermatophytic infections in the Department of Dermatology and Central Microbiology Laboratory of Shree Balaji Medical College and Hospital, Chrompet, Chennai. A total of 80 cases of various types of dermatophytes were studied, diagnosed clinically and confirmed by culture and other tests. Patients who were above 40 years were taken, which includes both male and female. Among these, 40 patients belong to DIABETIC population, 18 females and 22 males were included and 40 patients belong to NON-DIABETIC population which includes 21 females and 19 males.

\section{The relative incidence of different dermatophytes}

The number of cases studied and the percentage of incidence of various dermatomycoses is given in the following table.

The most commonly isolated Dermatophyte was Trichophyton ruburum (45\%) and the next common was Trichophyton mentagrophyte (17.5\%) followed by Microsporum gypseum (15 \%), Epidermophyton floccosum (5\%). 7 samples didn't have significant growth (17.5\%)

The most commonly isolated Dermatophyte among Non-diabetic patients is Trichophyton rubrum $(35 \%)$ and the next common was 
Trichophyton mentagrophyte (20\%) followed by Microsporium gypseum (15\%), 12 samples didn't show any significant growth with $30 \% .7$ samples didn't have significant growth, with $17.5 \%$.

\section{Trichophyton rubrum}

Totally 32 patients were infected with $40 \%$ of incidence among both Diabetic and Nondiabetic

\section{Trichophyton mentagrophyte}

Totally 15 patients were infected with $17.5 \%$ of incidence among both diabetic and nondiabetic patients.

\section{Microsporium gypseum}

Totally 12 patients were infected with $15 \%$ of incidence among both diabetic and nondiabetic patients

\section{Epidermophyton floccosum}

Totally 2 patients were infected with $2.5 \%$ of incidence among both diabetic and nondiabetic patients

The incidences of dermatophyte infection are quite higher in Chennai ${ }^{(106)}$. In this study 80 samples were taken, 40 Diabetic and 40 NonDiabetic patients samples were taken in which among the diabetic patients $22(55 \%)$ were males and 18 (45\%) were females. In NonDiabetic patients $19(47.5 \%)$ were males and $21(52.5 \%)$ were females.

Chuku Aleruchi et al., (107) in May 2012 showed that males were more prone to get dermatophytic infection than the females. The lower incidence in females may be because of the social stigma prevailing. Higher incidence in male may be correlated with the occupational hazards related to their nature of work, interaction with different people of the society, environmental conditions also plays an important role such as hot and humid weather, poor personal hygiene and low illiteracy rate plays an important role in frequency of dermatophytosis in this part of the country which was observed by Kamalam A, Thambiah AS (1976) ${ }^{(108)}$; Nwadiaro $2003^{(109)}$.

In this study patients above 40 years of age were taken from both diabetic and nondiabetic patients. Dermatophyte infection is more common above 20 years as shown in the studies of Sing D, Patel DC, Rogers K, Wood $\mathrm{N}$, Riley D, Morris AJ ${ }^{(110) \text {. }}$

A total number of 80 samples were collected,

Skin scrapings -64

Nail clippings -15

Hair sample - 1

Dermatophytes require keratin for growth, they are restricted to superficial skin, hair, nail. This is the reason why they do not invade the mucosal surface.

Some dermatophyte spread directly from one person to another (Anthrophillic dermatophytes).Others live in and are transmitted to humans from soil (geophilic organisms), and still others spread to humans from animal hosts. Transmission of dermatophytes also can occur indirectly from fomites (e.g., upholstery, hairbrushes, \& hats).

Anthropophilic organisms are responsible for most fungal skin infections. Transmission can occur by direct contact or from exposure to desquamated cells. Direct inoculation through breaks in the skin occurs more often in persons with depressed cell-mediated immunity. Once fungi enter the skin, they germinate and invade the superficial skin layers. 
Dermatophytes are classified as anthropophilic, zoophilic or geophilic according to their normal habitat

\section{ANTHROPOPHILIC}

Epidermophyton floccosum

Microsporium audouinii

Microsporium ferrugineum

Trichophyton concentricum

Trichophyton kanei

Trichophyton megninii

Trichophyton mentagrophytes

Trichophyton raubitschekii

Trichophyton rubrum

Trichophyton schoenleinii

Trichophyton soudanense

Trichophyton tonsurans

Trichophyton violaceum

Trichophyton yaoundei

\section{ZOOPHILIC}

Microsporium canis

Microsporum equinum

Microsporum nanum

Microsporum persicolor

Trichophyton equinum

Trichophyton mentagrophyte

Trichophyton simii

Trichophyton verrucosum

\section{GEOPHILIC}

Microsporium gypseum

Trichophyton ajelloi

Trichophyton terrestre

Comprehensive study of the dermatophytic infections in the Department of Dermatology and Central Microbiology Laboratory

\begin{tabular}{|c|c|c|}
\hline & MALE & FEMALE \\
\hline DIABETIC & 22 & 18 \\
\hline NON-DIABETIC & 19 & 21 \\
\hline
\end{tabular}

Fig.1

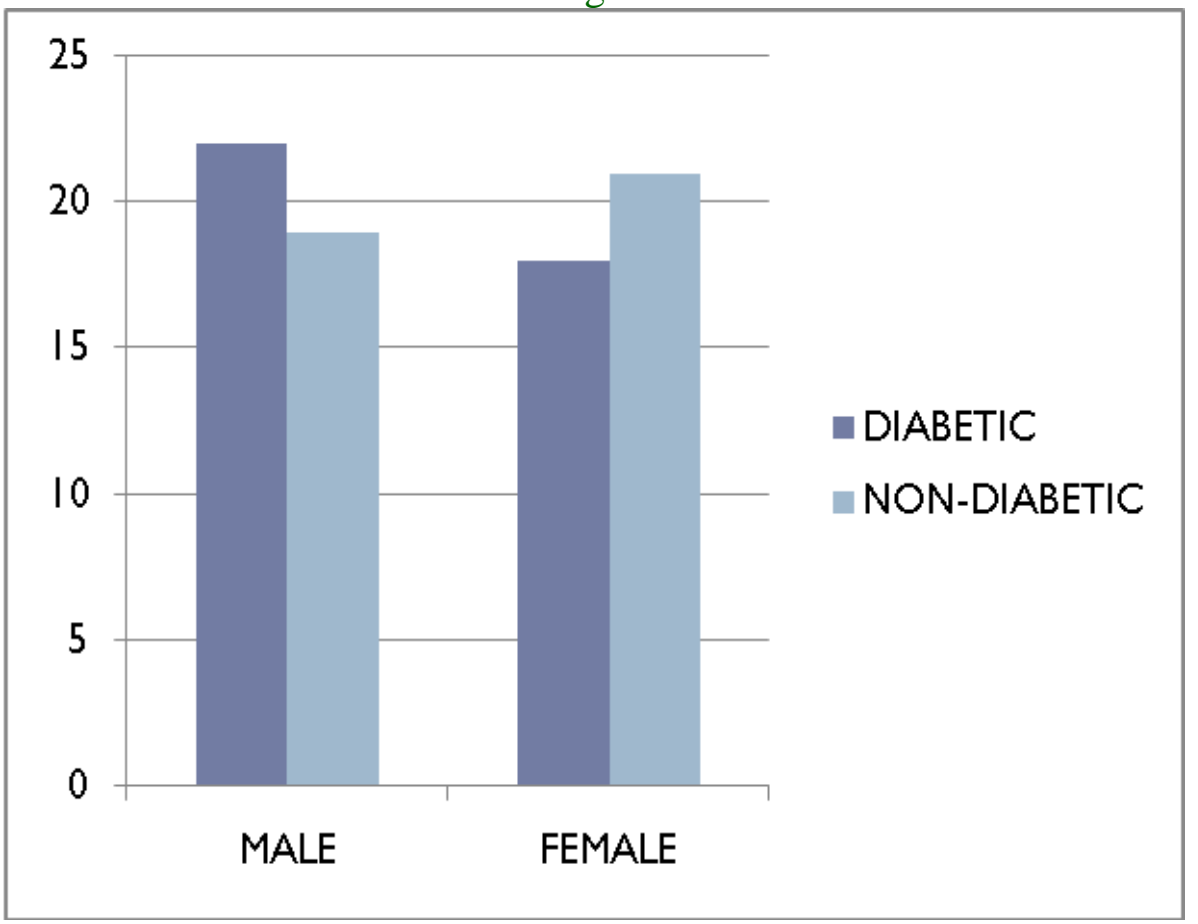


Fig.2

The male and female ratio in Diabetic population is 11:9

The male and female ratio in non-diabetic patients is 9:10

Percentage of specimens from different sites of collection

\begin{tabular}{|l|l|l|l|}
\hline $\begin{array}{l}\text { TOTAL NO.OF } \\
\text { SPECIMEN }\end{array}$ & SKIN SCRAPPING & NAIL CLIPPING & HAIR \\
\hline 80 & 64 & 15 & 1 \\
\hline
\end{tabular}

Fig.3 Frequency of incidence

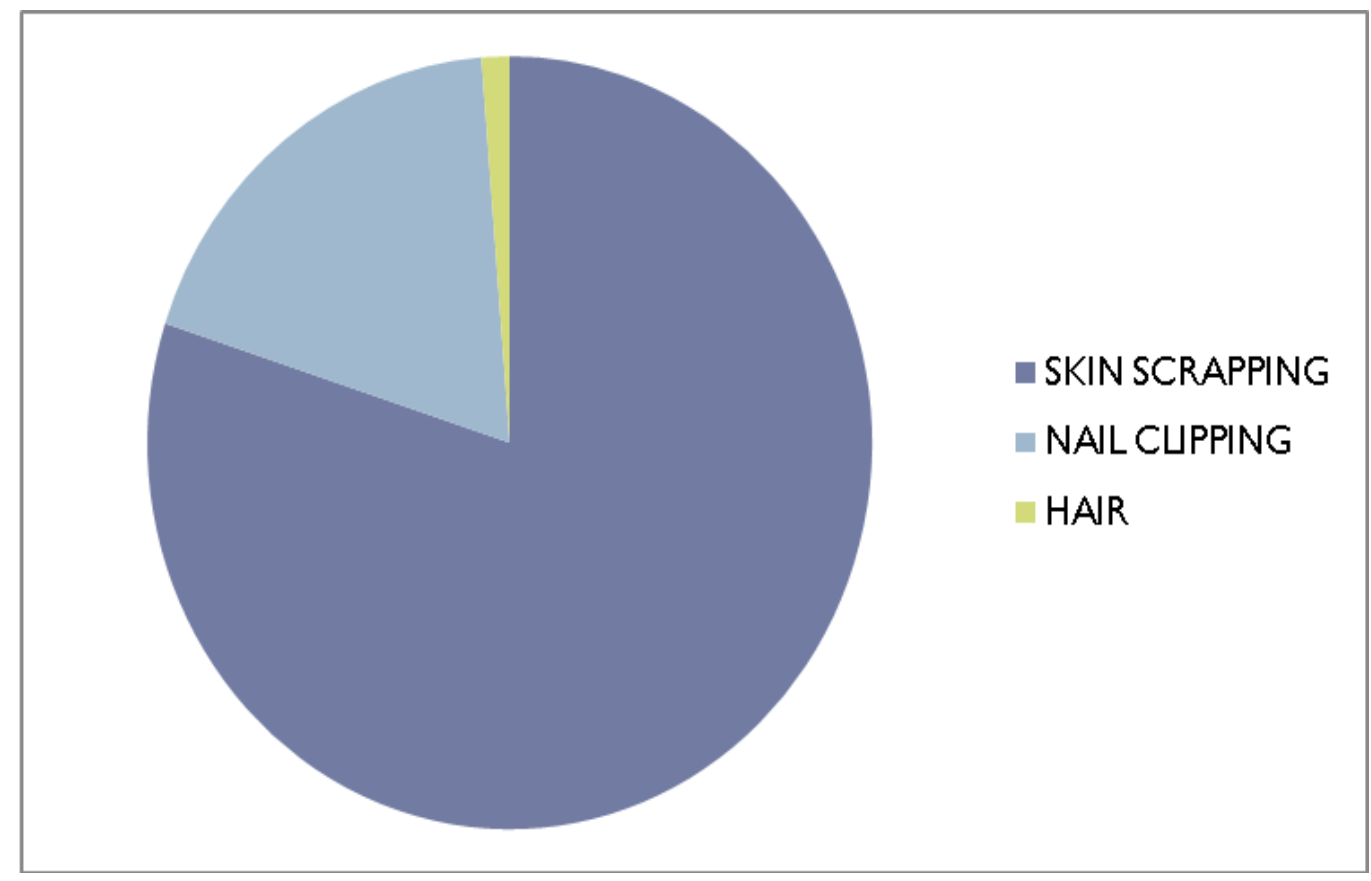


Fig.4

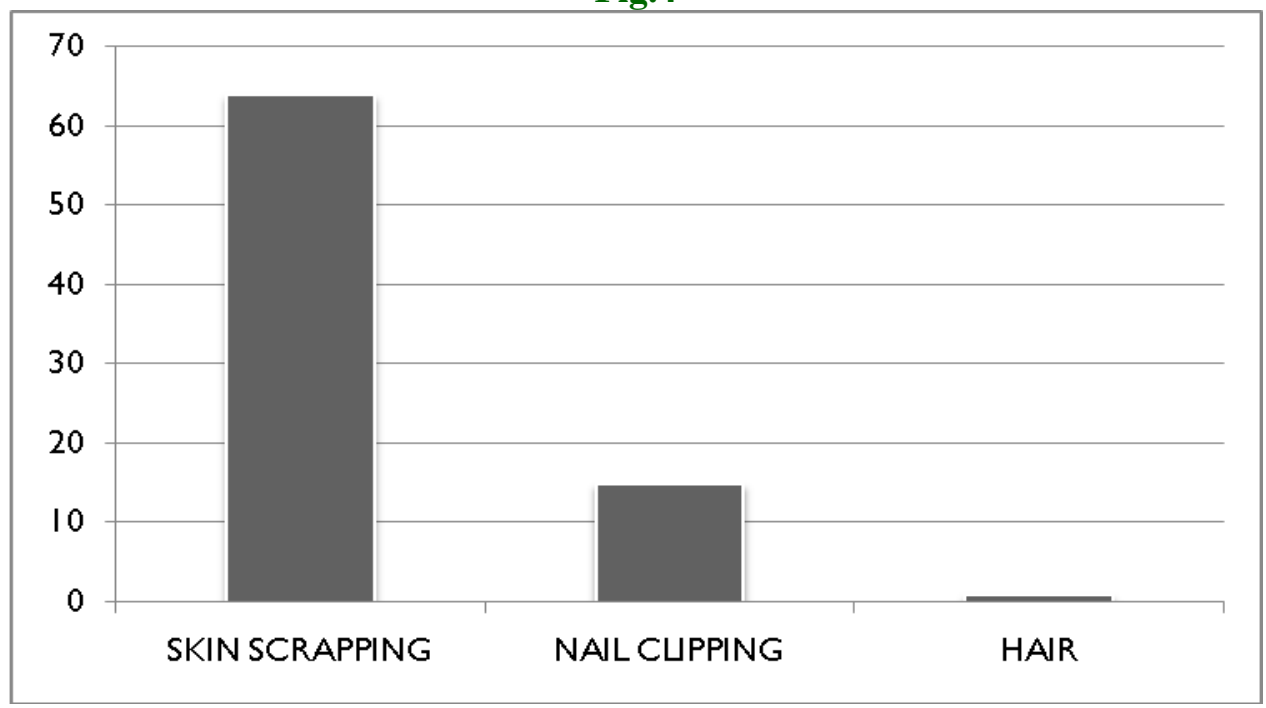

Out of 80 specimens collected, 64 were skin scrapings, 15 were nail clippings and 1 was hair sample.

Types of dermatophytes in diabetic

\begin{tabular}{|l|l|l|l|}
\hline $\begin{array}{l}\text { SPECIMEN } \\
\text { COLLECTION }\end{array}$ & $\begin{array}{l}\text { TYPE OF } \\
\text { DERMATOPHYTE }\end{array}$ & NO.OF CASES & PERCENAGE \\
\hline SKIN SCRAPING & T.rubrum & 15 & 37.5 \\
& T.mentagrophyte & 4 & 10 \\
\hline M.gypseum & 6 & 15 \\
\hline HAIR & E.floccosum & 1 & 2.5 \\
\hline NAIL CLIPPING & No growth & 1 & 2.5 \\
& T.rubrum & 3 & 7.5 \\
\hline & T.mentagrophyte & 3 & 7.5 \\
\hline & E.floccosum & 1 & 2.5 \\
\hline
\end{tabular}

Fig.5 Pie chart showing number of dermatophytes in skin scrapping

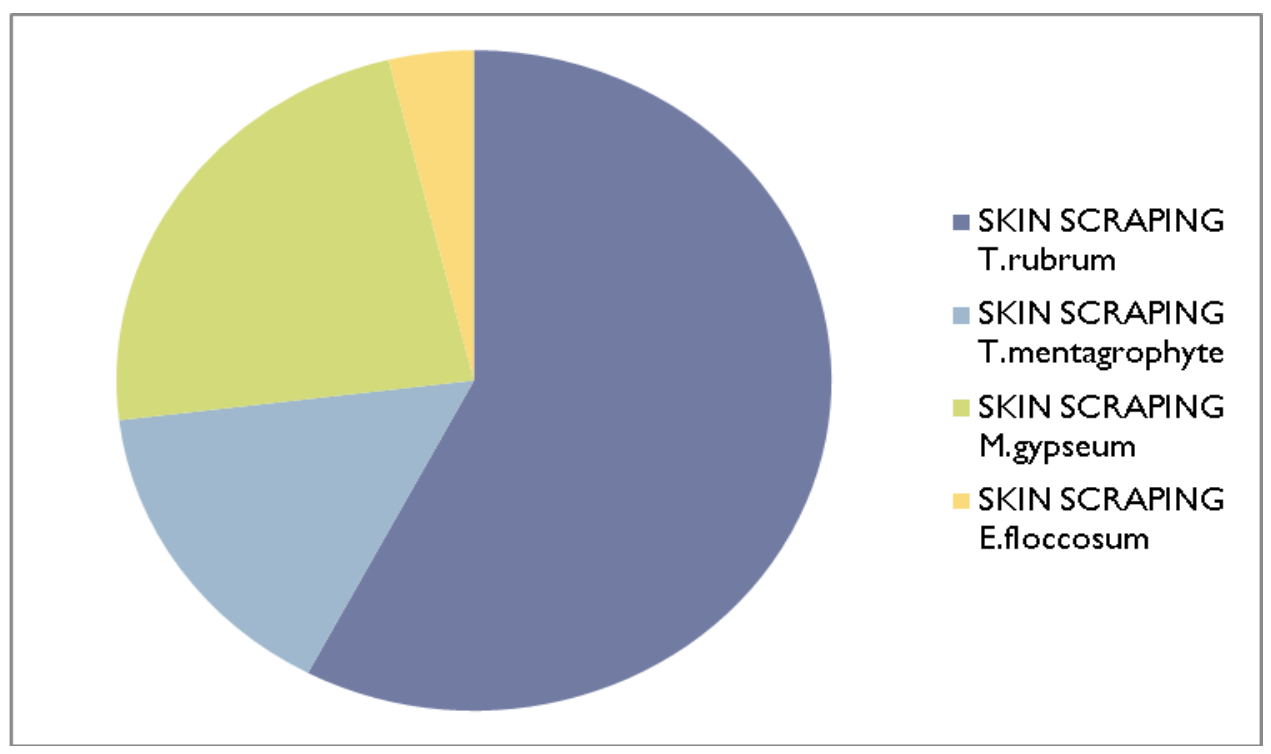


Fig.6 Pie chart showing number of dermatophytes in Nail clipping:

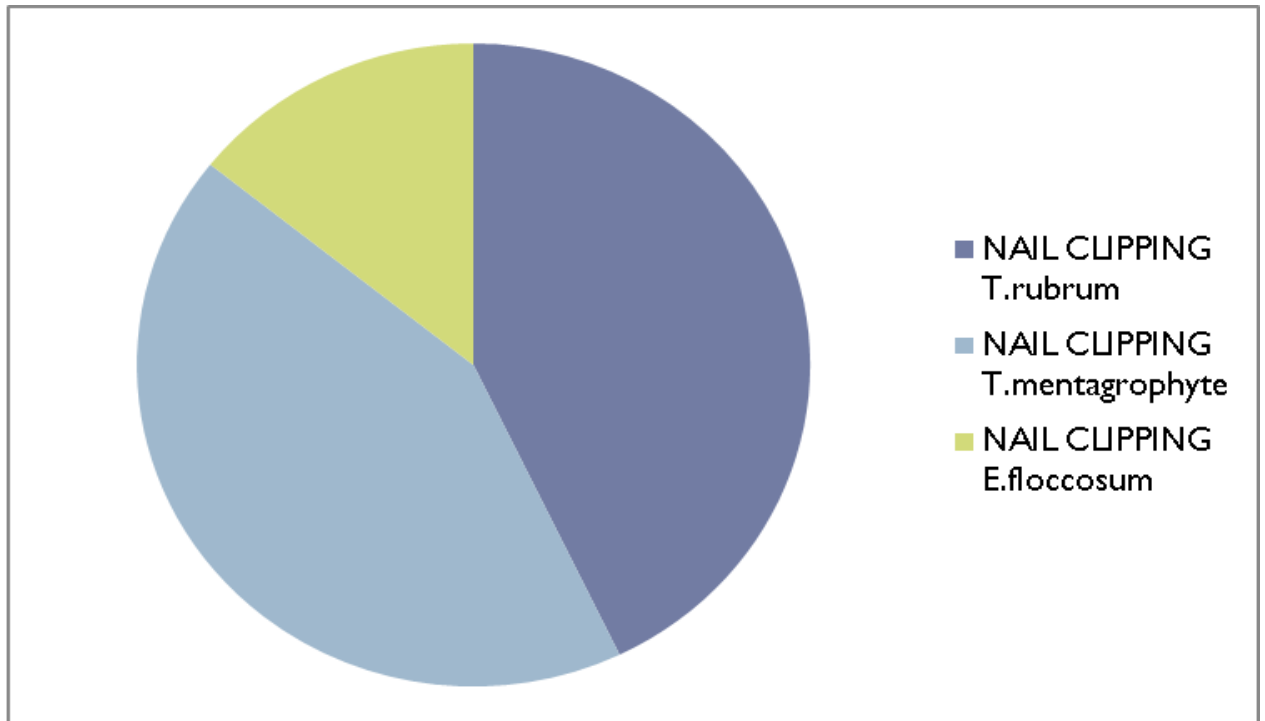

Total number of dermatophyte in non-diabetic patients

\begin{tabular}{|l|l|l|l|}
\hline $\begin{array}{l}\text { SPECIMIEN } \\
\text { COLLECTION }\end{array}$ & $\begin{array}{l}\text { TYPE OF } \\
\text { DERMATOPHYTE }\end{array}$ & NO.OF CASES & PERCENTAGE \\
\hline SKIN SCRAPING & $\begin{array}{l}\text { T.rubrum } \\
\text { T.mentagrophyte }\end{array}$ & 14 & 35 \\
& M.gypseum & 5 & 12.5 \\
\hline HAIR & No growth & 0 & 12.5 \\
\hline NAIL CLIPPING & T.rubrum & 0 & 0 \\
\hline & T.mentagrophyte & 3 & 0 \\
\hline M.gypseum & 1 & 7.5 \\
\hline
\end{tabular}

Fig.7 Pie chart showing number of dermatophytes in Skin scrapping

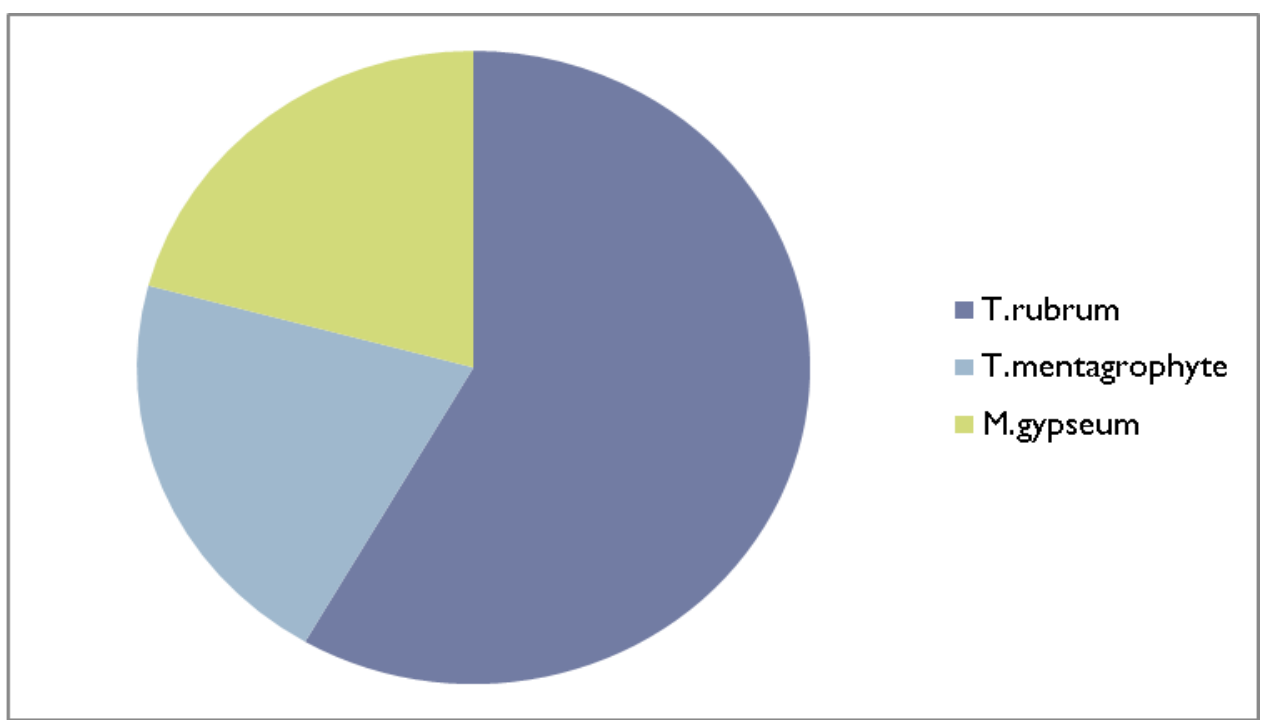


Fig.8 Pie chart showing number of dermatophytes in Nail clipping

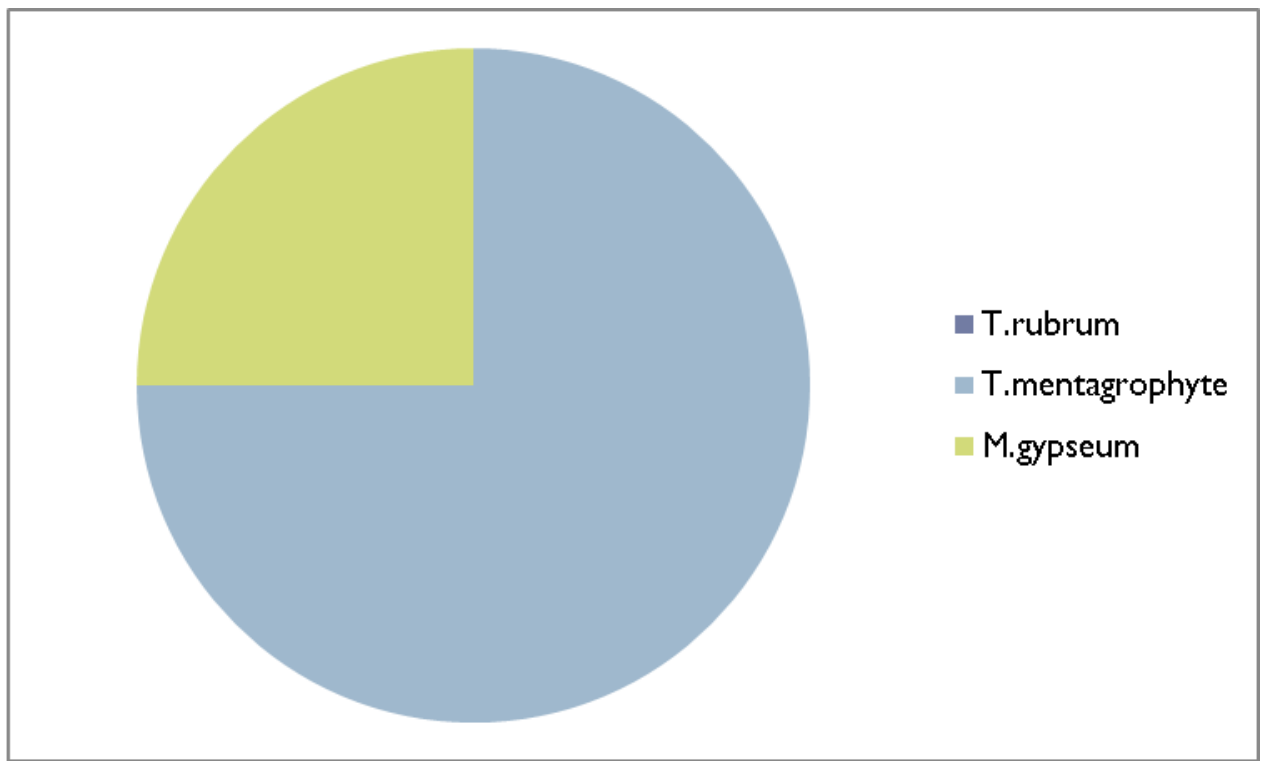

Diabetic Patients

\section{DERMATOPHYTE}

\section{NUMBER OF CASES}

\section{FREQUENCY OF INCIDENCE} (IN PERCENTAGE \%)

Trichophyton rubrum

Trichophyton mentagrophyte

Microsporum gypseum

Epidermophyton floccosum

\begin{tabular}{|c|c|}
\hline 18 & 45 \\
\hline 7 & 17.5 \\
\hline 6 & 15 \\
\hline 2 & 5 \\
\hline
\end{tabular}

Fig.9 Number of cases

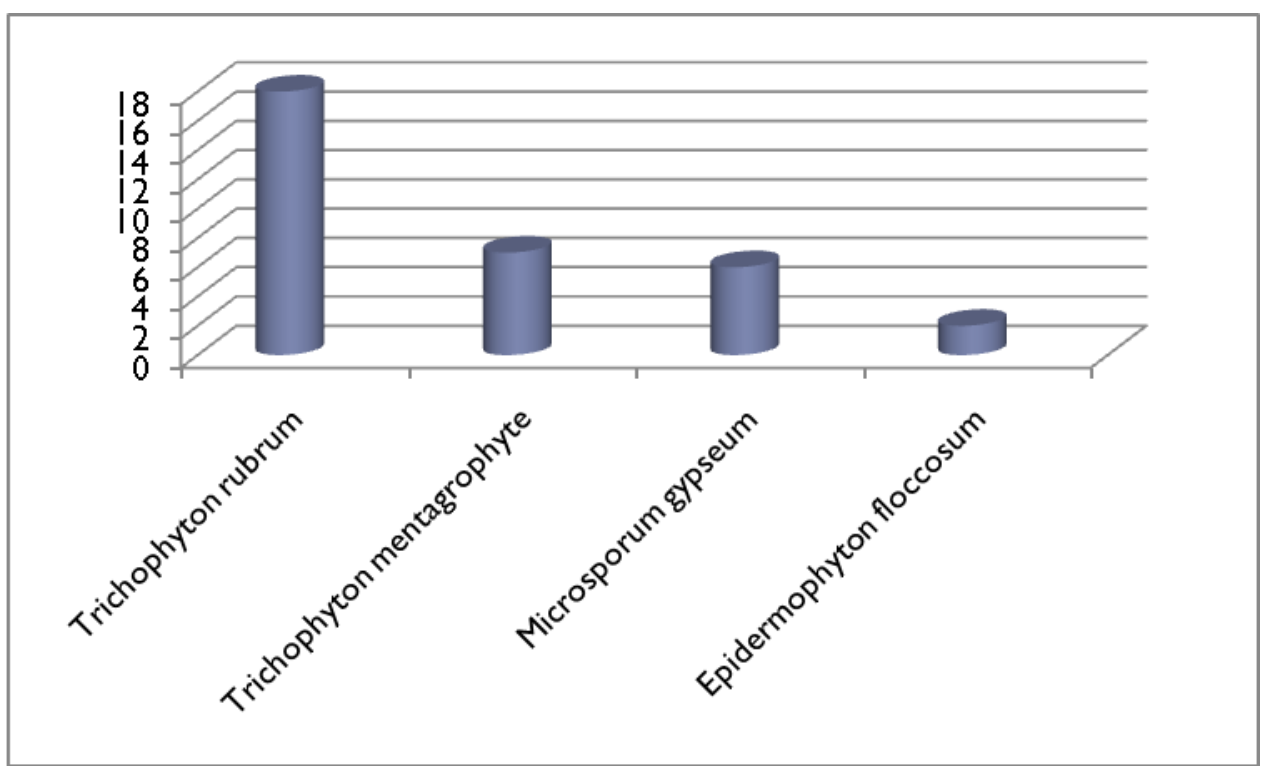


Fig.10

\section{FREQUENCY OF INCIDENCE}

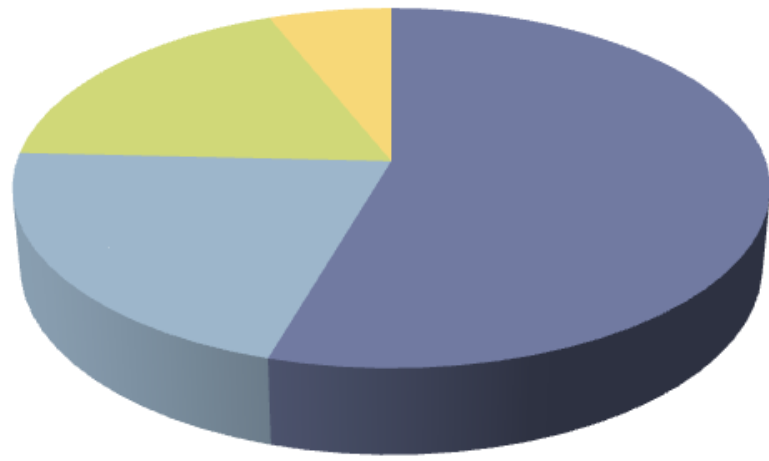

- Trichophyton rubrum

- Trichophyton mentagrophyte

Microsporum gypseum

Epidermophyton floccosum

Non-Diabetic

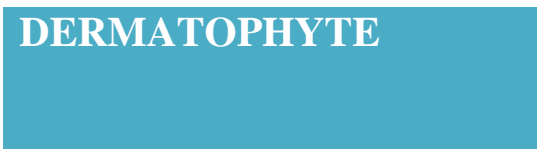

NUMIBER OF
CASES

FREQUENCY OF

INCIDENCE

(PERCENT \%)

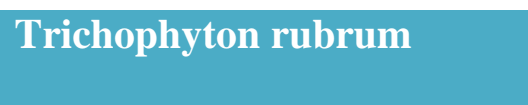

Trichophyton

mentagrophyte

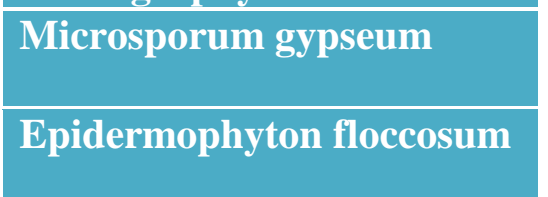

14

8

6

15

0

Fig.11

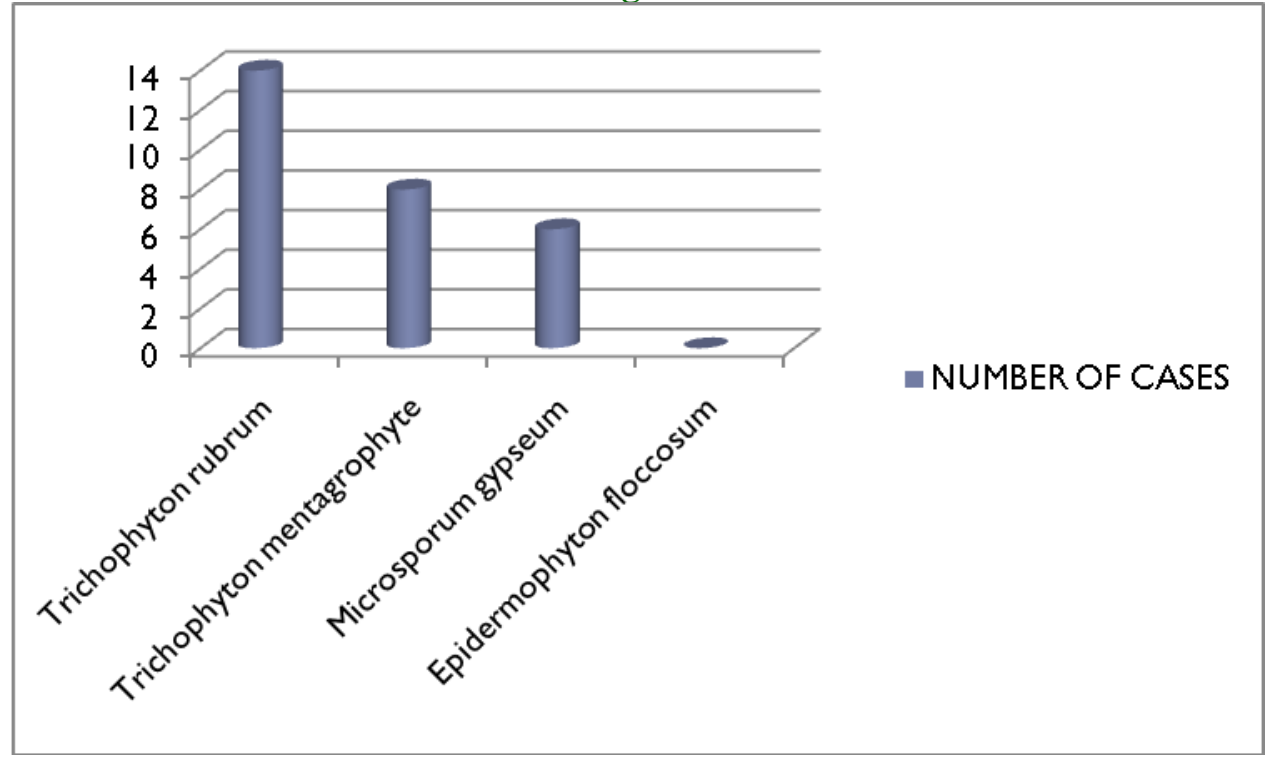


Fig.12

\section{FREQUENCY OF INCIDENCE}

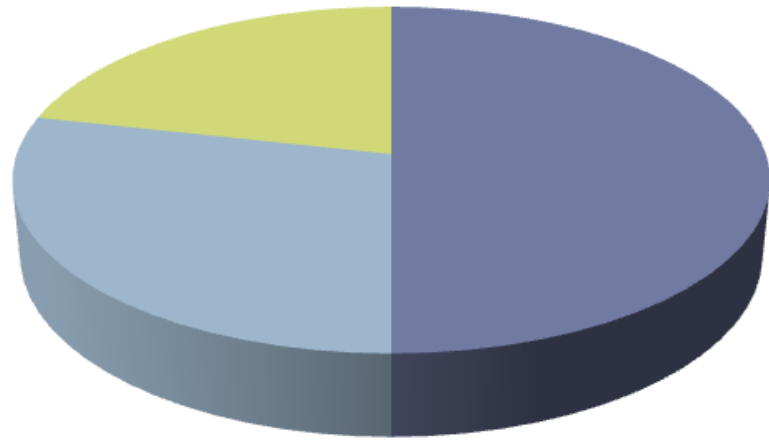

- Trichophyton rubrum

- Trichophyton mentagrophyte

Microsporum gypseum

Epidermophyton floccosum

Trichophyton rubrum

\begin{tabular}{|l|c|c|}
\hline \multicolumn{1}{|c|}{ SEX } & DIABETIC & NON-DIABETIC \\
\hline MALE & 10 & 9 \\
\hline FEMALE & 8 & 5 \\
\hline RATIO & $5: 4$ & $2: 1$ \\
\hline
\end{tabular}

Fig.13

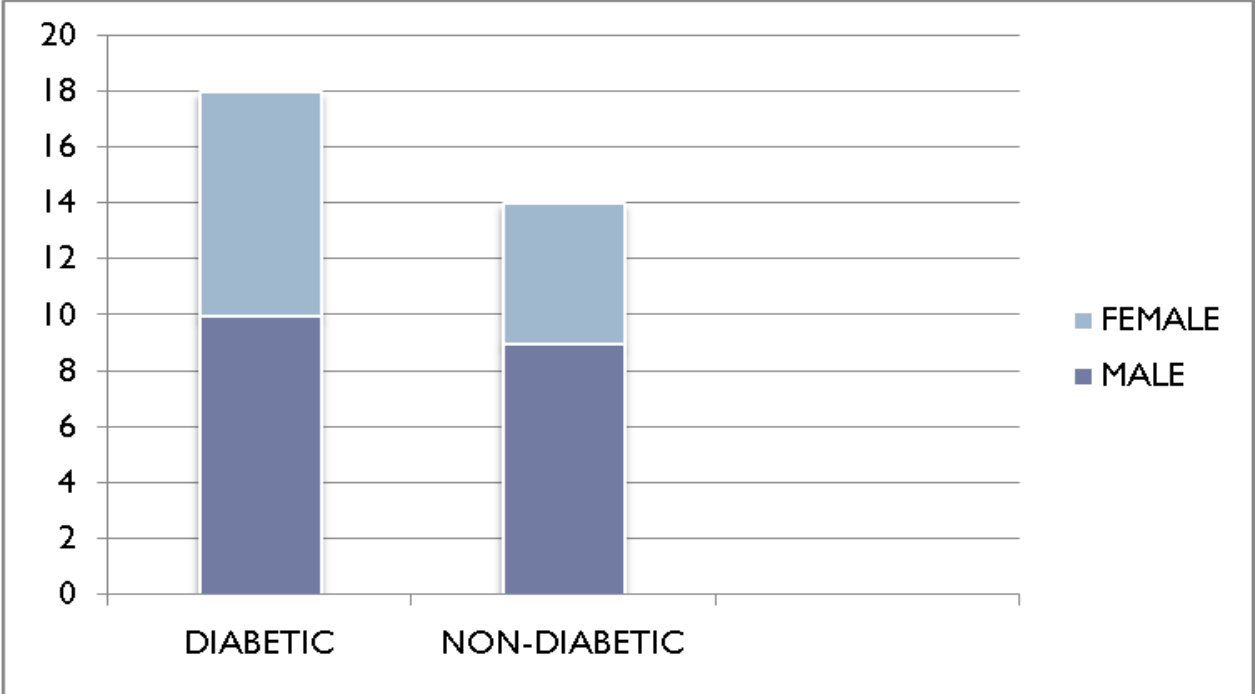

Trichophyton mentagrophyte

\begin{tabular}{|c|c|c|}
\hline SEX & DIABETIC & NON DIABETIC \\
\hline MALE & 5 & 2 \\
\hline FEMALE & 2 & 6 \\
\hline RATIO & $2.5: 1$ & $3: 1$ \\
\hline
\end{tabular}


Fig.14

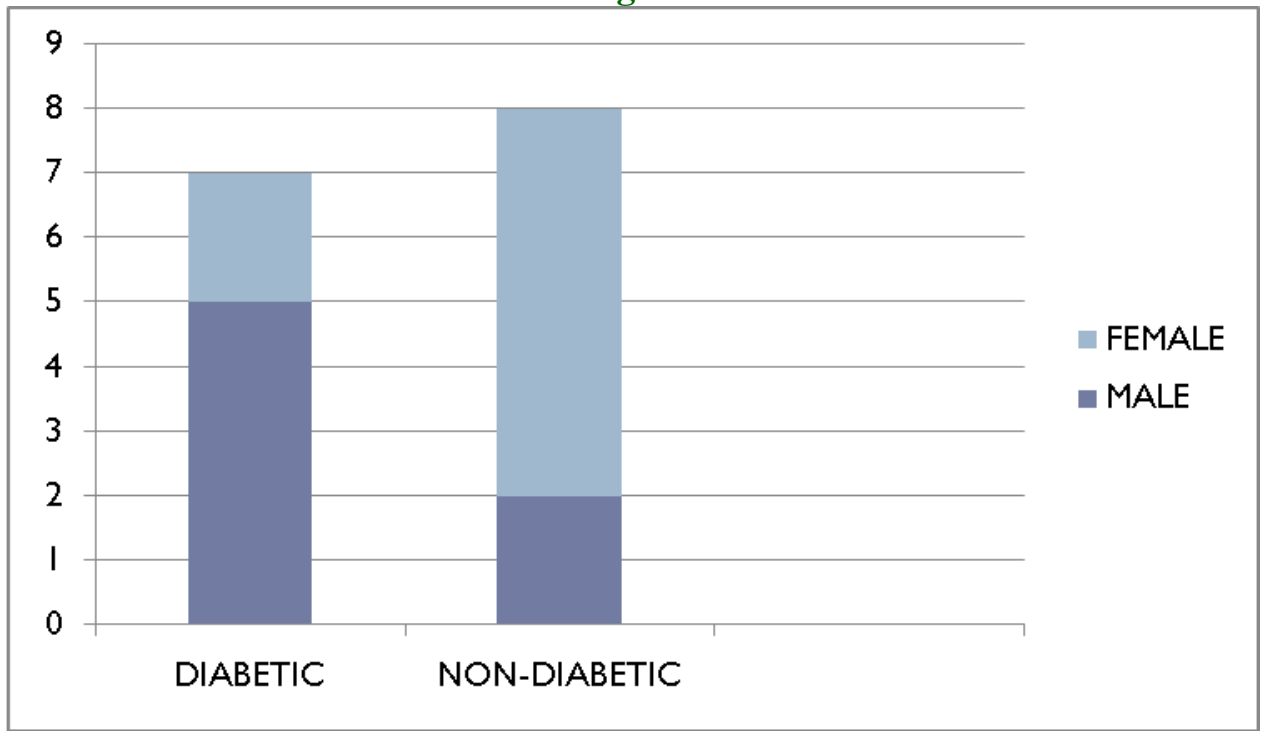

Microsporium gypseum

\begin{tabular}{|c|c|c|}
\hline SEX & DIABETIC & NON DIABETIC \\
\hline MALE & 2 & 1 \\
\hline FEMALE & 4 & 5 \\
\hline RATIO & $1: 2$ & $1: 5$ \\
\hline
\end{tabular}

Fig.15

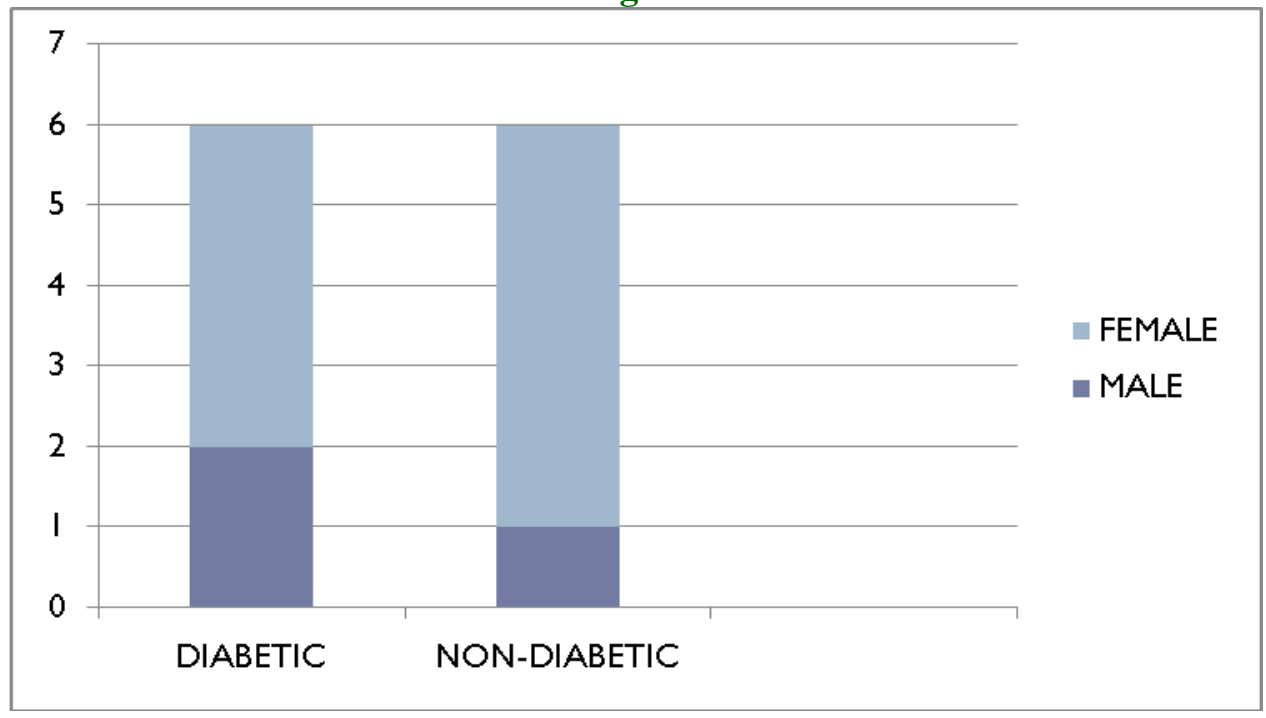

Epidermophyton floccosum

\begin{tabular}{|c|}
\hline SEX \\
\hline MALE \\
\hline FEMALE \\
\hline RATIO \\
\hline
\end{tabular}

\begin{tabular}{|c|c|}
\hline DIABETIC & NON DIABETIC \\
\hline 0 & 0 \\
\hline 2 & 0 \\
$0: 2$ & $0: 0$ \\
\hline
\end{tabular}


Fig.16

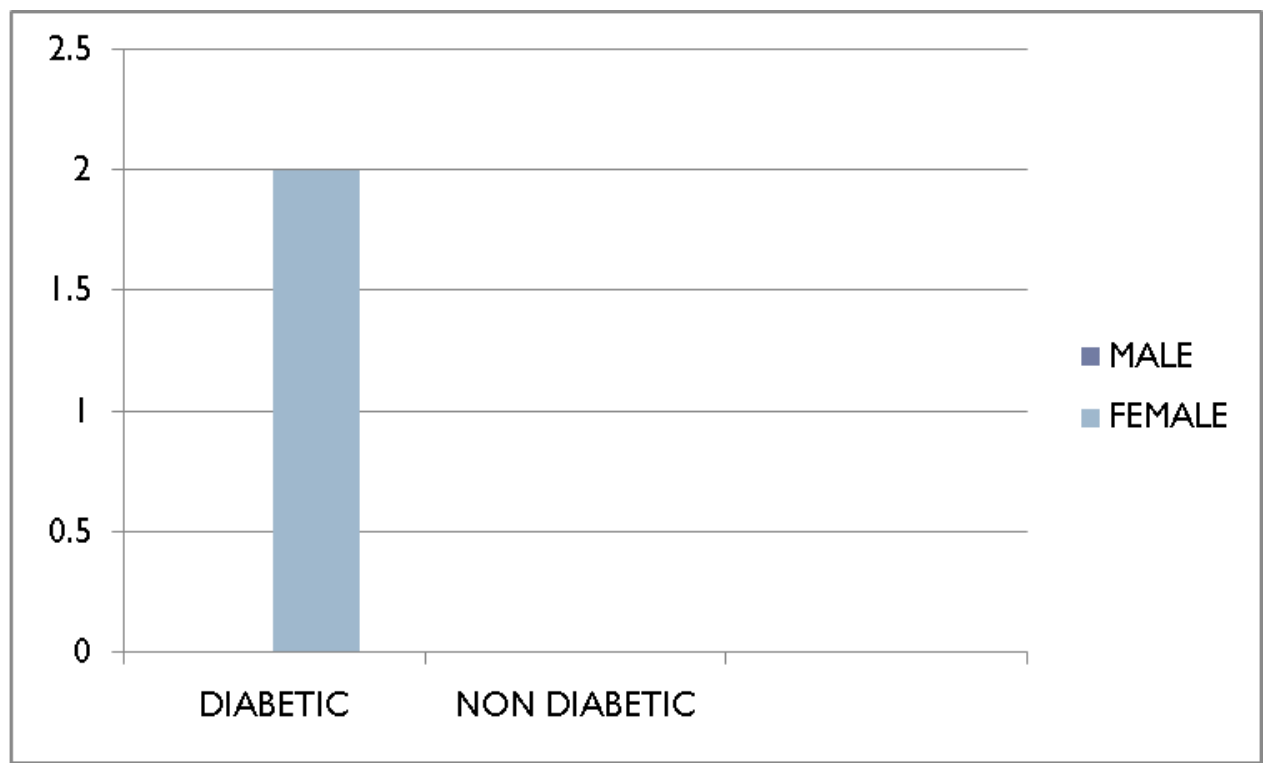

The global incidence of onychomycosis is increasing and it continues to spread and persist as shown by studies of $\mathrm{R}$ Kaur, $\mathrm{B}$ Kashyap, P Bhalla (111), Mashkoor Ahmad, Sanjay Gupta, Satish Gupte (112), Vera Leibovici, Klilah Hershko, Arieh Ingber, Maria Waterman, Nurit Leviatan-Strauss, Malka Hochberg ${ }^{(113)}$

The higher incidence of dermatophytic infection in skin is because dermatophyte requires keratin for their growth as said by Barry L. Hainer ${ }^{(114)}$

Out of the 40 diabetic isolates, 25 (62.5\%) isolates belong to Trichophyton spp. of which T. rubrum was the predominate isolate $(45 \%)$ followed by $T$. mentagrophyte $(17.5 \%)$ In Kannan et al., ${ }^{(115)}$ studies $T$. rubrum was the main isolate $(81 \%)$. This coincides with most of the earlier works of Pandey, 1970; Verenker, 1991; Summana and Singaracharya, 2004.

T. mentagrophyte was the second most commonly isolated species $7 / 40(17.5 \%)$ this is confirmed by the studies of Urmil Mohan et $a l$., where the isolation rate was $28.2 \%$. Mehta
JP et al., and Nagakatti PS et al., have also recorded an isolation rate of $22 \%$ and $29 \%$. Further, 6(15\%) belong to Microsporum spp. of which one species $M$. gypseum was isolated. Two isolates belonged to Epidermophyton floccosum (5\%).

The members of the genera of Epidermophyton spp. 2 of $40(5 \%)$ and Microsporum spp. 6 of 40 (15\%) accounted for lower percentage of infection when compared to Trichophyton spp. as in Kannan et al., ${ }^{(115)}, 2006$ studies, where 2 of 53 (3.7\%) infections were due to Epidermophyton spp. Out of the 40 non-diabetic patients 14 of 40 isolates belong to $T$. rubrum $(35 \%)$ remains the predominant dermatophyte followed by $T$. mentagrophyte $8 / 40$ (20\%). Total number of Trichophyton spp. isolated accounts for $22(55 \%)$ followed by $M$. gypseum which accounts for $6(15 \%)$. In the non-diabetic group also Microsporum spp. accounts for lower percentage of infection when compared to Trichophyton spp. in Kannan et al., 2006 (115) studies.

In an epidemiological survey of dermatophytosis in Tehran 2000 to 2005 
Shahindokht et al., (116) have found that Epidermophyton floccosum accounted for $85 \%$ of the infections, which is the most prevalent fungal pathogen.

\section{Trichophyton rubrum}

In this study out of the 80 patients 32 isolates were $T$. rubrum. $T$. rubrum is the most common dermatophytic infection and this finding is confirmed by a study done by Suman S, Beena PM in Gujarat India, same finding was shown by a research work done by Suganthi in Chennai. The climatic condition, socioeconomic status and the geographical location in which this part of Chennai falls prove to be an important cause for the higher incidence. Overall, 18/32 patients were diabetic and 14 of 32 were nondiabetic patients. There is a higher prevalence of $T$. rubrum in diabetic patients when compared to non-diabetic patients. As shown by Farheen et al., T. rubrum was most prevalent in males than the females. $T$. rubrum infection is usually transmitted from man to man. In this connection the work done by English in Great Britan Rothman and Many in United States shows significant $T$. rubrum infection in families and have found the familial transfer of this infection. Rare instances of $T$. rubrum infections in animals are available in literature. Kaplan and Gump have reported the occurrence of $T$. rubrum infections in dog. T. rubrum is an anthropophilic dermatophyte. Two types of $T$. rubrum have been distinguished: T. rubrum downy type and $T$. rubrum granular type. The downy strain has become the most widely distributed dermatophyte of man. The granular strain is a frequent cause of tinea corporis.

\section{Trichophyton mentagrophyte}

Totally 15 isolates of $T$. mentagrophyte were isolated from 80 patients. Among these 7 patients were diabetic and 8 were nondiabetic patients. T. mentagrophyte is the second most commonly isolated to T. rubrum this is confirmed by the studies of Urmil Mohan et al., There were 5 males and 2 females among the diabetic patients and 2 males and 6 females among non-diabetic patients. T. mentagrophyte var. $T$. mentagrophyte is the zoophilic form of $T$. mentagrophytes with a worldwide distribution and a wide range of animal hosts including mice, guinea pigs, kangaroos, cats, horses, sheep and rabbits. This is the reason for lower incidence of $T$. mentagrophyte as they are found more common in animals than the humans.

\section{Microsporum gypseum}

Totally 12 isolates of $M$. gypseum were isolated from 80 patients. Among these 6 patients were diabetic and 6 were nondiabetic. 2 patients were male and 4 patients were female among the diabetic, and 1 was male and 5 females in non-diabetic patients. Genus Microsporum contains a number of important species that are the principle causative agents of animal and human dermatophytoses ${ }^{(119)}$ it is the most common cause for tinea and ringworm infection. This is usually found in children's and rural workers in warm humid weather, this may be the reason why there is a lower incidence of $M$. gypseum in this study as the study population is more than 40 years of age.

\section{Epidermophyton floccosum}

Totally 2 isolates of E. floccosum were isolated from 80 patients. Both the isolates are from diabetic patients who where females. $E$. floccosum represents the species with the lowest predominance in the study period considered. This result could be interpreted as indicative of species that nowadays have a low clinical relevance and may tend to 
disappear from our community this is confirmed by the work done by Sara Asticcioli, Adriano Di Silverio, Laura Sacco, Ilaria Fusi, Luca Vincenti, Egidio Romero from Italy ${ }^{(118)}$. E. floccosum causes tinea pedis, tinea corporis, and onychomycosis. It is not known to invade hair in vivo and no specific growth requirement has been reported. E. floccosum infection may become epidemic among personnel using common shower or gym facilities, e.g. athletic teams, troops, ship crews and inmates of institutions.

Out of the four different types of dermatophytes isolated among 40 diabetic patients, 18 samples showed T. rubrum with $45 \%$ isolation rate. $T$. rubrum is the most commonly isolated dermatophyte, similar results have been shown by a study done by Nita Patwardhan from Aurangabad were the isolation rate of $T$. rubrum was $28.12 \%$, in another study the isolation rate was $46 \%$ which was done by Isac Alteras and Ety Saryt from Israel. Further, 15 isolates of T. rubrum was positive from skin scrapings and 3 was from nail clippings. The higher incidence of T. rubrum from skin scrapings may be because of the reason that dermatophytes require Keratin for their growth as shown by Barry 1. Hainer ${ }^{(114)} 2003$, it is also increased by human to human contact, socioeconomic status, and it is mostly found in the rural population. Geographical conditions also play an important role. Among the non-diabetic patients 14 samples were positive for $T$. rubrum. As shown by Isac Alteras and Ety Saryt in both diabetic and non-diabetic patients $T$. rubrum was the most common dermatophyte, $45 \%$ in diabetic patient and $57.5 \%$ among non-diabetic patients as compared to this study which shows $45 \%$ for diabetic and $35 \%$ for non-diabetic patients.

Next to $T$. rubrum, the second most commonly isolated dermatophyte in diabetic population is T. mentagrophyte and it was isolated from 7 samples $(17.5 \%)$. This observation is confirmed by work done by Suman Sing, P.M. beena ${ }^{(118)}$. Similar study by Isac Alteras and Ety Saryt from Israel show an isolation rate of $21 \%$ and $25 \%$ was the isolation rate from a study done by Nita Patwardhan from Aurangabad. Four samples were isolated from skin scrapings and 3 samples were isolated from nail clipping the reason for this because of the utilization of keratin by dermatophyte has shown by Barry Hainer $2003^{(114)}$.

Among non-diabetic patients 8 samples were positive for T. mentagrophyte, 5 samples were taken from skin scrapings and 3 samples from nail clippings

M. gypseum is the third commonly isolated dermatophyte among the diabetic population, 6 samples showed $M$. gypseum growth with an isolation rate of $15 \%$. All the samples were isolated from skin scrapping this is confirmed by the study done by chowdhary which shows an isolation rate of $0.59 \%$. Among the nondiabetic patients 6 samples were positive for $M$. gypseum, 5 were taken from skin scrapping and 1 sample from nail clipping

E. floccosum was the least isolated species among diabetic population, 2 samples had growth of E. floccosum with an isolation rate of $5 \%$ this is confirmed by a similar study done in Chennai by Suganthi which showed an isolation rate of $7.1 \%$, in another study done by Khalique from Aurangabad the isolation rate is $5.8 \%$.

There was only one hair sample and there was no significant growth, further culture and $\mathrm{KOH}$ also showed negative.

80 Samples from 80 patients suspected of dermatophytic infections were collected and processed. It includes 40 diabetic patients and 40 non-diabetic patients.

The male /female ratio was 51\%: $48 \%$. 
Patients above 40 years of age were taken from both diabetic and non-diabetic patients.

A $16.3 \%$ of cases gave a history of contact with possible source of infection.

Of the 40 diabetic samples collected 7 samples $(17.5 \%)$ were both negative for both $\mathrm{KOH}$ wet mount and culture, remaining 33 samples $(82.5 \%)$ were positive for both $\mathrm{KOH}$ mount and culture.

Out of the 40 non-diabetic patients 12 samples $(30 \%)$ were negative for both $\mathrm{KOH}$ mount and culture, remaining $28(70 \%)$ were positive for both $\mathrm{KOH}$ mount and culture.

The samples were skin scrapings, hair, and nail. Of the culture positive cases, $58.7 \%$ belonged to Trichophyton spp., $15 \%$ Microsporum spp. and $2.5 \%$ to Epidermophyton spp.

The predominant isolate from all samples were $T$. rubrum, $40 \%$ from both diabetic and non-diabetic patients. T. rubrum was found predominantly in diabetic patients with an isolation rate of $45 \%$ than in the non-diabetic patients were the isolation rate is $35 \%$.

T. mentagrophyte isolation rate was $18.7 \%$ from both diabetic and non-diabetic patients.

Isolation rate of $T$. mentagrophyte was more from non-diabetic patients $(20 \%)$ than the diabetic patient with the isolation rate of $17.5 \%$.

Microsporum gypseum isolation rate was $15 \%$ from both diabetic and non-diabetic patients.

Isolation rate of $M$. gypseum (15\%) was same among both diabetic and non-diabetic patients.

Epidermophyton floccosum was the least isolated dermatophyte with an isolation rate of $5 \%$ and it was isolated only from diabetic patients.

\section{References}

Aananthi C, and Sarayu L. A study of chronic dermatophyte infection in a rural hospital. Indian J Dermatol Venereol Leprol 2005; 71: 129.

Ainsworth G.C and Austwick, P.C.K 1955 A survey of animal mycosis in Britain, General aspect Vet, Record 67: 88-97

Ajello 1 et al., 1934 The natural history of Microsporum nanum. Mycologia, Vol-LVI, No: 6, 873-884, (nov-dec 1964)

Ajello. L 1953 The Dermatophyte, Microsporum gypseum as a saprophyte and parasite J.Invest.Dermat Vol 21, No 3 (Sep-1953)

Ajello.L 1960 Geographic distribution and prevalence of the Dermatophytes, The N.Y Acad Sci Vol 89, Art I 30-38

Bub JL, and Olerud JE. Diabetes Mellitus: In Fitzpatrick TB, Freedberg IM, Eisen AZ et al., (editors). Dermatology in General Medicine, Vol 2, 6th edn. NewYork: McGraw-Hill; 2003. p. 1651-55.

Dodge, C.W 1935 Medical mycology, St. Louis C.V Mosby Company pp 466

Emmons, C.W 1934, Dermatophytes- Natural grouping based on the form of spores and accessory organs, Arch. Dermat, Syph, 30: 337-362

Foot Fungus in Diabetics: Drugs Aging. 2004; 21(2): 101-12. Related Articles, Links Common fungal infections of the feet in patients with diabetes mellitus. Tan JS, Joseph WS. Department of Internal Medicine, Northeastern Ohio Universities College of Medicine, Ohio, USA.

Fowle L.P and George L.K Suppurative ringworm contracted from Cattle. Canad.Med Assoc J 41: 234-235

Fox h 1926 Ringworm of the scalp in adult, Report of case of kerion due to microsporum audouinii ibid 13: 398 (March) 1926

Fox H and Fowkes R.W 1925 Ringworm of the scalp in adults Arch Dermat and Syph II:466 (April) 1925 
Gentles J C and O' Sullivan J.G 1957 Correlation of human and animal ringworm in West Scotland Brit Med J (II): 678-682.

George L.K 1962 A new species of Microsporum pathogenic to man and animals, Sabourauds, Vol 1, Part 4.

George L.K Charles, S. Robert D.V.M et al., 1957 Trichophyton mentagrophyts infections in dogs and cats. The journal of American Veterinary Med Assoc VOl 130, No-10, pp 427-432.

George L.K Eugene A, H and Robert A.M 1956 Observation of rural and urban ringworm J.Invest, Dermat. Vol 27 no 5 (Nov 1956)

Hattemn SV, Boots MA, Thio HB. Skin menifestations of diabetes. Cleveland Clin J Med 2008; 75: 772-87.

Jillson O.F and Buckley W.R 1952 Fungus disease in man acquired from cattle and horse, New England Med, 246: 996-999

Kaplan W and George L.K \& Ajello L 1958 Recent development in animal ringworm and their public health implications. Annals of the N.Y Acad Sci Vol 70 Arts 3, pp 636649, (June 1958).

Kaplan W and George L.K 1957 Isolation of Microsporium Audouinii from a Dog J.Invest. Dermat Vol 28 no 4 (April 1957)

Kaplan, W and George, L.K and Ajello.L 1958, Recent development in animal ringworm and their public health implications. Annals of the N.Y Acad. Sci, Vol, 70 Arts3, pp 636-649, (June 1958)

LA Touche C.J 1952 The Leeds campaign against Microsporosis in children and domestic animals Vet Record 64: 398-399.

Mahajan S, Koranne RV, Sharma SK. Cutaneous manifestation of diabetes mellitus. Indian $J$ Dermatol Venereol Leprol 2003; 69: 105-8.
Manges R.W and George L.K Survey of animal ringworm in the united states Public Health Reports J.S 72 : 503-509.

Manges R.W, Jory $\mathrm{j}$ et al., Ringworm in wild Animals in Southwestern Georgia. The American Journal of Veterinary Research. Vol18 no 68, July 1957 pp 672-677

Mc Keever S, Manges R.W et al., 1958, Ringworm fungi of Feral Rodents in Southern Georgia. The Am.J of Vet Research Vol 19 No 73 oct, 1958, 969-972

Mc Pherson E.A 1957 A survey of the incidence of ringworm in cattle in Northern Britan Vet Record 69: 674-679.

Nigham PK, and Pande S. Pattern of dermatoses in diabetics. Indian J Dermatol Venereol Leprol 2003; 69:83-5.

Pernet G 1925 Ringworm of the scalp; Reprt of case in adults Arch. Dermat and Syph 12: 267

Rao.A Mycotic disease in India -A critical review. Bulletin of school of tropical medicine calcatta 1959: 13-22

Rippon J.W. Medical Mycology, Dermatophytosis and Dermatomycosis, 3rd edition, P 238

Tamil Nadu Metrological Department Survey

The Electronic textbook of Dermatology: Diabetes in Skin infection Art huntly M.D, Rhett Drugee M.D

Torres G and George L.K 1956 A human case of Trichophyton Gallinae infection A.M.A Arch of Dermat, 74: 191-197

Van Houtum WH. 5th International symposium on the diabetic foot. Diabetes Metab Res Rev. 2008; 24(Suppl 1): S1-S2.

Wilds Roglic G, Green A, Sinee R, King H: Global prevalence of diabetes estimate for the year 2000 and projections for 2030. Diabetes care 2004; 27: 1047-1053.

\section{How to cite this article:}

Dinesh Kaliyamoorthi . 2018. Prevalence of Dermatophytic Infection among Diabetic and NonDiabetic Patients in a Tertiary Level Hospital in Chennai, India. Int.J.Curr.Microbiol.App.Sci. 7(06): 2516-2536. doi: https://doi.org/10.20546/ijcmas.2018.706.298 